\title{
ORIGEM SOCIAL E RISCO DE REPETÊNCIA: INTERAÇÃO RAÇA-CAPITAL ECONÔMICO
}

\author{
FÁTIMA ALVES \\ Doutoranda do Programa de Pós-Graduação em Educação \\ Pesquisadora-Assistente do Laboratório de Avaliação da \\ Educação do Departamento de Educação \\ da Pontifícia Universidade Católica do Rio de Janeiro \\ dcalves@edu.puc-rio.br \\ ISABEL O RTIGÃO \\ Programa do Mestrado em Educação, Cultura e \\ Comunicação da Universidade Estadual do Rio de Janeiro \\ isabelortigão@terra.com.br \\ CRESO FRAN CO \\ Programa de Pós-Graduação em Educação da Pontifícia \\ Universidade Católica do Rio de Janeiro \\ creso@edu.puc-rio.br
}

\section{RESUMO}

A despeito de melhora expressiva no fluxo escolar durante a maior parte da década de 1990 , especialmente entre 1992 e 1998, a repetência tem-se mantido constante e em valor elevado desde 1998. Dados provenientes dos dois últimos censos das escolas indicam leve tendência de aumento da repetência. Usamos dados do Sistema Nacional de Avaliação da Educação Básica - Saeb/200/-, para investigar a relação entre origem social e risco de repetência de alunos que cursavam a $8^{a}$ série do ensino fundamental em escolas públicas de capitais brasileiras. O resultado da estimação de modelos de risco para repetência mostrou que diversas variáveis de origem social continuam associadas ao aumento do risco da repetência, no sentido usualmente descrito pela literatura educacional. Mostrou também que embora capital econômico acima da média atue como fator de proteção para a repetência, esse resultado não prevalece para todos os grupos raciais, pois alto capital econômico mostrou-se fator de risco para os alunos que se autodeclararam pretos. Conseqüências dos resultados para políticas públicas são discutidas

REPETÊNCIA - CLASSE SOCIAL - RAÇA - POLÍTICAS PÚBLICAS

Versões preliminares deste trabalho foram apresentadas na $28^{a}$ Reunião Anual da Associação Nacional de Pesquisa em Educação - Anped -, Grupo de Trabalho de Sociologia da Educação, em Caxambu, 2005, e no $3^{\circ}$ Colóquio Luso-Brasileiro de Questões Curriculares, em Braga, 2006. 


\section{ABSTRACT}

SOCIAL ORIGIN AND RISK OF SCHOOL FAILURE: RACE-ECONOMIC CAPITAL. Retention rate in Brazil is constant and still high since 1998, despite major improvement in its educational flux during the decade of 1990. Moreover, administrative data from the last two years indicates some tendency of greater retention. Using data from the $200 /$ Brazilian Assessment of Educational Progress, $8^{\text {th }}$ grade, we investigated the relationship between social background and risk of retention in primary and middle school of Brazilian states capitals. The result of the estimation of logistic risk models for retention pointed out that several socio-demographic variables are associated to an increased risk of retention, something that is well in line with the findings already described in the literature. We also identified that if above average economic status protects against retention, this is not a homogeneous result for all race subgroups: for black students, this variable is associated to an increased risk of retention. Consequences for educational policy are discussed.

GRADE REPETITION - SOCIAL CLASS - RACE - PUBLICS POLICIES

Alta taxa de reprovação é problema de longa data na educação brasileira (Freitas, 1947; Brandão, Baeta, Rocha, 1983; Costa-Ribeiro, 1991). Ainda que a reprovação tenha diminuído no Brasil, em especial durante parte da década de 1990, a não-aprovação (reprovação e abandono) estabilizou-se na
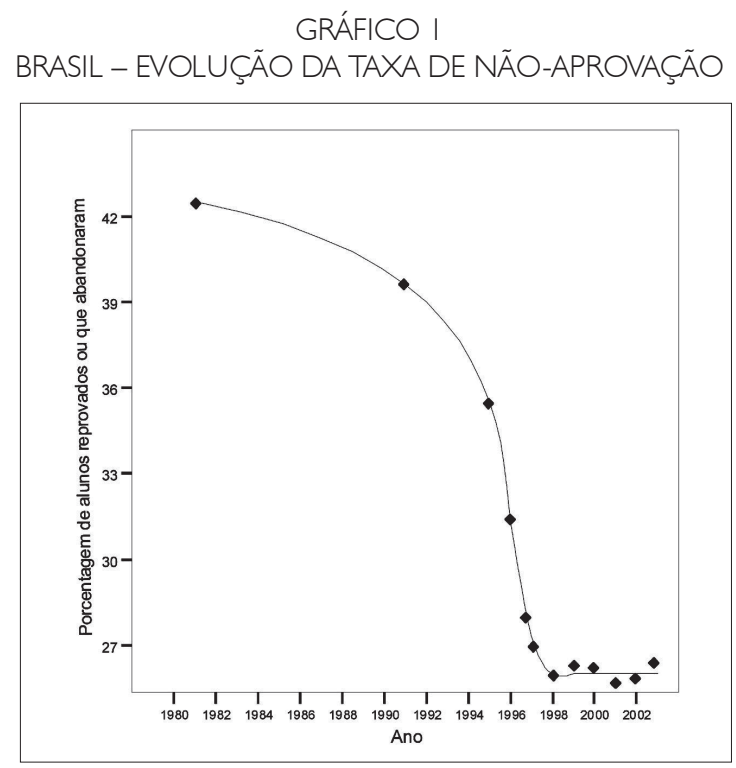
faixa de 26\%, patamar ainda extremamente elevado. $\bigcirc$ gráfico I ilustra essa situação. Devemos ressaltar ainda que a apuração da taxa de reprovação para o ano de 2004, ainda não publicada, indica tendência de aumento.

Alguns autores investigaram o efeito de variáveis sociodemográficas sobre o risco de repetência (Gomes-Neto, Hanushek, 1994; Souza, Silva, 1994; Leon, Menezes-Filho, 2002), mas, até onde sabemos, não há estudos brasileiros sobre o tema da interação entre variáveis de origem social sobre a probabilidade de repetência'. Neste artigo apresentamos o resultado de estudo sobre o efeito tanto do capital econômico das famílias e da cor declarada dos alunos como da interação dessas variáveis sobre o risco de repetência dos alunos.

A repetência escolar é um fenômeno social complexo em cuja produção interagem características da escola, do aluno e da família. A preocupação com o chamado "fracasso escolar", principalmente das crianças pobres, deu origem a inúmeras pesquisas nas últimas décadas. Patto (1996), com base em ampla revisão de literatura, mostra que as explicações dadas para esse "fracasso" ao longo da história apresentam diferentes ênfases, destacando-se as deficiências do aluno (de origem médica ou psicológica), os fatores intra-escolares e a carência cultural do ambiente em que vive, sendo que esta última prevalece, ainda que sob diferentes feições, até os nossos dias.

Nos últimos anos, a "cultura do fracasso" começou a ser repensada de modo a incluir questionamentos sobre o papel da instituição escolar. As pesquisas educacionais desenvolvidas nos últimos 30 anos evidenciaram que as escolas são diferentes, não apenas porque possuem opções pedagógicas diversificadas, mas principalmente porque umas são melhores do que as outras com relação aos resultados escolares. Em outras palavras, algumas escolas conseguem agregar mais valor aos seus alunos do que outras, mesmo considerando alunos oriun-

I. Parte expressiva da literatura tem tratado indistintamente os pares de conceitos "aprovação" e "promoção"; "reprovação" e "repetência"; "abandono" e "evasão". No âmbito do sistema de informação e avaliação da educação brasileira, os conceitos de "aprovação", "reprovação" e "abandono" se aplicam dentro de um ano letivo. Ao final do ano letivo o aluno é aprovado, reprovado ou abandona a escola. Já os conceitos de promoção, repetência e abandono se aplicam entre anos letivos. Na transição entre um ano letivo e o seguinte, o aluno é promovido (quando cursa, no ano letivo subseqüente, a série seguinte), é repetente (quando cursa, no ano letivo subseqüente, a mesma série do ano anterior) ou evade-se (quando não se matricula na escola no ano subseqüente). 
dos de contextos socioeconômicos semelhantes. Entretanto, do ponto de vista teórico, a sociologia da reprodução ainda é referência sobre o papel da escola na atualização das desigualdades de origem socioeconômica e cultural.

Em continuidade aos trabalhos sobre as desigualdades educacionais, estudos desenvolvidos na área da Sociologia têm focalizado a atenção principalmente para as estratégias educativas familiares (Forquin, 200 I; Lahire, 1997; Nogueira, 1991; Romanelli, 1994). Nos últimos anos a família tornou-se um objeto de estudo privilegiado, não apenas no que se refere aos aspectos econômicos, mas principalmente no que diz respeito a como nesta instituição se instauram esforços para o acesso e para a distribuição de bens simbólicos e materiais entre seus membros.

A existência de contexto familiar caracterizado por ambiente de apoio aos estudos permite que os alunos tenham desempenhos escolares melhores:

...é na família, com sua configuração determinada, que se conjugam as características de seus componentes, como o sexo e a idade, e se socializam chances diferenciadas de participação na educação, no mercado de trabalho, na qualificação, entre os vários membros familiares. (Bonamino, Franco, Fernandes, 2005, p. 6)

Na seqüência deste artigo tratamos dos seguintes temas: apresentamos nossa apropriação da noção estendida de capital, desenvolvida por Coleman e por Bourdieu, e discutimos como a noção estendida de capital pode articular-se com a investigação empírica sobre repetência. Prosseguimos delineando o método que utilizamos na investigação sobre fatores de risco para a repetência. Em seguida, usamos técnicas estatísticas descritivas para explorar o tema da relação entre repetência e origem social, com base em dados do Saeb 200 I . Finalmente, apresentamos os resultados dos modelos de risco estimados e discutimos os resultados.

\section{REPETÊN CIA ESCO LAR SO B O ENFO QUE DOS CAPITAIS}

Bourdieu e Coleman introduziram o conceito de capital na análise social para referir-se não apenas à sua forma econômica, mas também à sua forma cultural e social. $\bigcirc$ termo capital foi utilizado por esses autores no estudo 
das desigualdades escolares, como metáfora para falar das vantagens culturais e sociais que indivíduos ou famílias possuem conduzindo-os, geralmente, a um nível socioeconômico mais elevado.

A concepção ampliada do conceito de capital desses sociólogos advém de evidências empíricas que apontam as limitações do conceito de capital econômico para explicar plenamente a ligação entre nível socioeconômico e resultados educacionais, fazendo-os considerar outras formas de capital, tais como o capital social e cultural. O conceito de nível socioeconômico continua englobando a idéia de "uma posição relativa na hierarquia social", mas é ampliado e passa a ser entendido como "o estoque de capital social possuído por um indivíduo ou família, incluindo capital econômico, cultural e social".

Os membros dos diferentes grupos sociais, com base nos exemplos de sucesso ou fracasso vividos por seus filhos no sistema escolar, e como parte de suas estratégias educativas, tendem a ajustar os investimentos às probabilidades de êxito de seus filhos na carreira escolar. A natureza e a intensidade dos investimentos de caráter escolar variam também em razão da manutenção da posição social atual ou da possibilidade de ascensão. Willms ( 1998) destaca que os pais de classe média se sentem bastante confortáveis na relação com os profissionais da escola e no envolvimento com as atividades nela desenvolvidas. Freqüentemente, esses pais possuem uma gama de estratégias para que seus filhos se adaptem à vida escolar, isto é, para que gostem do currículo (que normalmente valoriza os padrões de linguagem da cultura legítima) e alcancem o que a família considera ser o melhor para eles (por exemplo, ascensão social).

Coleman ( 1988) alerta para a importância dos efeitos da origem familiar no desempenho escolar dos filhos. Do ponto de vista analítico, essa origem envolve três componentes: capital econômico, capital humano e capital social. ○ econômico, medido aproximadamente pela renda e riqueza da família, fornece o recurso físico: espaço reservado para estudar e materiais apropriados; o capital humano, medido aproximadamente pela educação dos pais, proporciona um ambiente cognitivo que ajuda na aprendizagem dos filhos; e o capital social, que é a relação entre pais e filhos e, caso a família inclua outros membros, a relação com estes também.

O conceito de capital social baseado na família (Coleman, 1988) é particularmente frutífero nos estudos que envolvem a relação entre contexto familiar e desempenho escolar. Uma investigação realizada em escola pública 
distrital americana revelou bem a dinâmica do capital social, na qual se verificou que um número considerável de famílias asiáticas migrantes comprava sempre duas cópias de cada livro didático indicado pelos professores. $\bigcirc$ segundo livro destinava-se ao estudo da mãe, para que pudesse auxiliar seu filho a ter um bom desempenho na escola. De acordo com Coleman (1988) esse é um caso no qual o capital humano dos pais (medido tradicionalmente pelos anos de escolaridade) é baixo, mas o capital social (relação entre pais e filhos) disponível na família para a educação dos filhos é extremamente alto. Esse autor deixa bastante claro que os filhos são afetados pelo capital humano dos pais, mas, afirma ainda que "se o capital humano possuído pelos pais não for complementado pelo capital social incorporado nas relações familiares, ele é irrelevante para o crescimento educacional dos filhos" (p. I l0). Portanto, o capital social familiar depende, entre outros fatores, da presença física de adultos e da qualidade da relação.

Em outro estudo, Coleman (1988) discute os efeitos da falta de capital social familiar nas taxas de não conclusão do ensino secundário, com base em uma amostra de estudantes da avaliação High School and Beyond. Em relação à variável "presença dos pais" (proxy de capital social), os resultados indicam que a porcentagem de estudantes que saem da escola entre o fim do ano letivo da $2^{\mathrm{a}}$ série e o fim do ano letivo da $4^{\mathrm{a}}$ série é $6 \%$ maior para estudantes de famílias de pais separados. Para a variável "número de irmãos" a taxa de não conclusão entre alunos da $2^{a}$ série é 6,4\% maior para aqueles que possuem quatro irmãos do que para os que têm somente um irmão. A análise conjunta dessas variáveis evidencia que entre alunos da $2^{\mathrm{a}}$ série com quatro irmãos e com a presença de um dos pais (pai ou mãe), a taxa de não conclusão é de $22,6 \%$. Entretanto, aqueles que têm um irmão e contam com presença do pai e da mãe, a taxa cai para 10,1\%. No que diz respeito à expectativa da mãe em relação aos filhos irem para a faculdade - uma medida da atenção dos adultos na família - há indicação de que para os alunos cujos pais não têm essa expectativa, a taxa de não conclusão é $8,6 \%$ maior do que para aqueles alunos cujos pais têm essa expectativa. As análises realizadas com os alunos da $2^{a}$ série que têm apenas um irmão, contam com a presença dos dois pais em casa e os pais têm expectativa de ida para a faculdade, têm a taxa de não conclusão de $8,1 \%$. Já um aluno com quatro irmãos, morando com apenas um dos pais e sem a expectativa de ida para a faculdade, a taxa sobe para $30,6 \%$. 
Na perspectiva deste trabalho, investigamos a associação entre a reprovação escolar e características familiares. Especificamente, construímos um modelo de risco para a repetência em função de fatores associados às características familiares e sociodemográficas do aluno, associadas aos diferentes tipos de capital. $\bigcirc$ indicador de repetência foi construído com base no questionário contextual do Saeb 200 I que inclui quantas vezes o aluno já repetiu o ano. As respostas do aluno foram agrupadas de forma a transformar a variável "repetência" de ordinal para dicotômica, assumindo os seguintes valores: sim, caso o aluno tenha sido reprovado ao menos alguma vez ao longo de sua trajetória escolar; e não, caso contrário. Na seqüência, são apresentados e discutidos os principais resultados sobre a distribuição social da repetência escolar na rede pública das capitais brasileiras. Este estudo envolveu alunos de $8^{a}$ série do ensino fundamental que fizeram o teste de Matemática do Saeb 200 I , em razão de certas características suas e de seu entorno familiar.

\section{MÉTODO}

\section{Q uestões de pesquisa}

- Quais características dos alunos estão associadas ao aumento ou à diminuição do risco de repetência escolar dos alunos da 8 a série do ensino fundamental de escolas públicas das capitais dos estados brasileiros?

- Como os diferentes tipos de capital (econômico, social e cultural) estão associados à probabilidade de ocorrência da repetência escolar dos alunos da 8 a série do ensino fundamental das escolas públicas das capitais brasileiras?

- $\bigcirc$ efeito do capital econômico sobre a chance de reprovação é homogêneo para os diferentes grupos raciais?

\section{Dados}

Para investigar essas questões, utilizamos os dados coletados pelo Sistema Nacional de Avaliação da Educação Básica (Saeb 200 I) referentes aos alunos da $8^{a}$ série do ensino fundamental, que fizeram o teste de Matemática. $\bigcirc$ 
Saeb é uma avaliação educacional, baseada em amostra probabilística complexa - envolvendo estratificação, conglomerados e pesos amostrais - dos estudantes matriculados nas $4^{\mathrm{a}}$ e $8^{\mathrm{a}}$ séries do ensino fundamental e no $3^{\circ}$ ano do ensino médio. Esse tipo de avaliação tem ocorrido sistematicamente a cada dois anos desde 1990, e desde 1995 é aplicado em todas as unidades federativas brasileiras ${ }^{2}$. Neste trabalho, com exceção de Boa Vista, capital de Roraima, que não apresentava um estrato específico para a rede pública, foram considerados os dados de alunos de $8^{a}$ série do ensino fundamental de escolas públicas urbanas das capitais brasileiras, totalizando 12.162 estudantes.

Cabe mencionar a adequação, assim como as limitações dos instrumentos do Saeb para responder às questões de pesquisa propostas. Primeiramente, a investigação dos fatores associados à repetência deve contar com boas medidas das características socioeconômicas do aluno, bem como de seu entorno familiar. Essas medidas são encontradas de forma satisfatória no questionário contextual do Saeb respondido pelo aluno. Uma limitação do questionário está relacionada à medida de repetência. $\bigcirc$ questionário dos alunos

TABELA I

ESTATÍSTICA DESCRITIVA DAS VARIÁVEIS DICOTÔMICAS UTILIZADAS NA ANÁLISE

\begin{tabular}{lc}
\hline Variáveis & Proporção \\
\hline Menino & 50,4 \\
Pardo & 45,0 \\
Preto & 13,6 \\
Trabalha & 23,0 \\
Mora com mais de 4 pessoas & 56,7 \\
Gosta de estudar Matemática & 62,7 \\
Está na média ou acima da média em comparação aos colegas & 81,5 \\
Instrução familiar até $4^{a}$ série & 26,0 \\
Instrução familiar de $5^{a}$ até I I ${ }^{a}$ série & 31,0 \\
Instrução familiar ensino superior & 10,2 \\
Posse de bens acima da média & 45,3 \\
Recursos educacionais acima da média & 59,8 \\
\hline
\end{tabular}

Fonte: Microdados do Saeb 200 I, elaboração dos autores.

2. Em $200 \mathrm{I}$, foram coletados dados sobre 50.300 alunos matriculados na $8^{\mathrm{a}}$ série do ensino fundamental e 2.825 escolas onde estes estudavam. 
perguntava se eles haviam repetido alguma série e quantas vezes, não oferecendo informações sobre a época e as condições em que a repetência ocorrera. Dessa forma não foi possível vincular a repetência às variáveis da escola e do professor. As variáveis consideradas, tanto na análise exploratória, quanto na modelagem do risco de repetência, encontram-se na tabela I.

\section{Abordagem analítica}

Começamos conduzindo análise exploratória bivariada, na qual simplesmente computamos o percentual de alunos com experiência prévia de repetência para as diversas categorias de resposta em variáveis que expressam origem social. Prosseguimos com a estimação de modelos multivariados de regressão logística, assumindo a experiência prévia de repetência como variável dependente. Assim, repetência é a variável de desfecho e as demais variáveis são os fatores de risco da repetência.

Neste trabalho apresentamos os resultados obtidos em função da exponenciação do coeficiente de cada um dos regressores. A exponenciação do coeficiente associado a uma variável representa a razão de chance (odds ratio $\mathrm{OR}$ ) que indica como as chances da repetência se modificam quando se transita entre diferentes categorias de um mesmo fator de risco, sendo a categoria de partida o nível adotado como nível de referência. Em outras palavras, a OR $(\exp b$,$) representa a mudança na chance de se observar o evento a ser pre-$ visto pelo modelo $(Y=1)$ quando a sua variável independente associada $\left(X_{1}\right)$ é elevada em uma unidade, mantendo-se todas as outras variáveis constantes.

Dessa forma, podemos caracterizar as variáveis independentes como um fator de risco ou de proteção de acordo com os valores da OR associada a cada variável. Quando a variável dependente está codificada de modo que o desfecho I é desfavorável (como no caso da repetência) e a OR de uma variável independente for menor do que I, esta variável é considerada um fator de proteção, pois a OR estima a diminuição do risco do evento ocorrer com o aumento de uma unidade desta variável. Já quando a OR de uma variável for maior do que I, ela é considerada um fator de risco, pois esse valor estima o aumento do risco da ocorrência do evento desfavorável.

Para este trabalho optou-se por realizar, inicialmente, um modelo de risco para a repetência sem a inclusão de termos de interação, no sentido de se 
verificar os efeitos dos diferentes tipos de capital. Posteriormente, analisou-se um modelo que incluiu a interação entre posse de bens de consumo e cor capital declarada, para verificar como o efeito do econômico é atenuado ou ampliado de acordo com a cor declarada.

\section{RESULTADOS}

\section{Estudo exploratório}

A repetência afeta o processo de escolarização e o aprendizado dos alunos, sendo responsável direta pela defasagem idade-série, pela evasão escolar e pelo afastamento do aluno de seus colegas de referência e de seu grupo etário (Leon, Menezes-Filho, 2002; Bonamino, Franco, Fernandes, 2005).

Na rede pública das capitais brasileiras, com exceção de Boa Vista, 47,5\% dos alunos da 8 a série do ensino fundamental já repetiram uma ou mais séries desde a $5^{a}$ série. Entretanto a repetência escolar não se distribui homogeneamente entre as regiões brasileiras. A tabela a seguir mostra que as regiões Norte e Nordeste apresentam os maiores percentuais de repetência, 57,4\% e 58,2\% respectivamente. A Região Sul apresenta o menor índice do país (39,4\%). Uma das possíveis explicações para os elevados percentuais de repetência na $8^{\mathrm{a}}$ série relaciona-se à adoção, em vários estados brasileiros, da organização da escolaridade em ciclos de aprendizagem. Esse tipo de política educacional tem sido apontado como um dos responsáveis pelo deslocamento de maiores percentuais de repetência para as séries mais avançadas do ensino fundamental.

TABELA 2

PERCENTUAL DE ALUNOS COM EXPERIÊNCIA PRÉVIA DE REPETÊNCIA POR REGIÕES DEMOGRÁFICAS, 8 a SÉRIE ESCOLAS PÚBLICAS DAS CAPITAIS BRASILEIRAS

\begin{tabular}{cccccc}
\hline \multicolumn{5}{c}{ Região demográfica brasileira } \\
\hline Repetência & Norte & Nordeste & Sudeste & Sul & Centro-Oeste \\
não & $42,6 \%$ & $41,8 \%$ & $60,6 \%$ & $56,0 \%$ & $53,2 \%$ \\
sim & $57,4 \%$ & $58,2 \%$ & $39,4 \%$ & $44,0 \%$ & $46,8 \%$ \\
\hline
\end{tabular}

Fonte: Saeb $200 \mathrm{I} / \mathrm{Inep}$. 
TABELA 3

PERCENTUAL DE ALUNOS COM EXPERIÊNCIA PRÉVIA DE REPETÊNCIA, 8 S SÉRIE ESCOLAS PÚBLICAS DAS CAPITAIS BRASILEIRAS, SEGUNDO AS VARIÁVEIS ANALISADAS

\begin{tabular}{|c|c|c|}
\hline & Variáveis / Categorias & $\begin{array}{c}\text { Experiência prévia } \\
\text { de reprovação } \\
\% \text { (nº de alunos) }\end{array}$ \\
\hline \multirow[t]{2}{*}{ Gênero } & Feminino & 42 \\
\hline & Masculino & 53 \\
\hline \multirow[t]{3}{*}{ Cor declarada } & Branca & 42 \\
\hline & Parda/mulata & 49 \\
\hline & Preta & 58 \\
\hline \multirow[t]{2}{*}{ Trabalha } & Não & 43 \\
\hline & $\operatorname{sim}$ & 63 \\
\hline \multirow[t]{2}{*}{ Número de moradores } & Até 3 pessoas & 43 \\
\hline & Mais de 3 pessoas & 50 \\
\hline \multirow[t]{2}{*}{ Posse de recursos educacionais } & Acima da média & 43 \\
\hline & Abaixo da média & 55 \\
\hline \multirow[t]{5}{*}{ Instrução familiar } & Até o ensino superior & 35 \\
\hline & Até o ensino médio & 40 \\
\hline & Até a 8 série & 50 \\
\hline & Até a $4^{\mathrm{a}}$ série & 55 \\
\hline & Sem instrução & 60 \\
\hline \multirow[t]{2}{*}{ Posse de bens econômicos } & Acima da média & 42 \\
\hline & Abaixo da média & 52 \\
\hline \multirow[t]{2}{*}{ Gosto pelo estudo da matemática } & Sim & 44 \\
\hline & Não & 54 \\
\hline
\end{tabular}

Fonte: Microdados do Saeb 200 I, elaboração dos autores.

A tabela 3 apresenta os resultados da porcentagem de alunos com experiência prévia de acordo com as diversas características consideradas na análise.

Com relação ao gênero, observa-se que o percentual de reprovação prévia entre os meninos é maior do que entre as meninas, 53\% e 42\% respectivamente. Esse resultado apresenta-se em consonância com o que tem sido preconizado pela literatura internacional, que registra a tendência de diferen- 
ças de gênero. No Brasil, os estudos que focalizam a temática das diferenças de gênero na educação indicam que uma das explicações relaciona-se à atribuição diferenciada do significado da escola entre homens e mulheres, principalmente no que se refere à sociabilidade e à liberdade (Madeira, Rodrigues, 1998).

Outro aspecto que podemos observar é que os alunos pretos possuem maior percentual de repetência. Esse resultado é compatível com outros encontrados na literatura específica, nos quais, sistematicamente, são reportados fatores associados à eficácia escolar. Existe um efeito negativo associado à cor declarada nos resultados educacionais (Franco, Mandarino, Ortigão, 2002; Albernaz, Ferreira, Franco, 2002; Barbosa et al., 200 I). Cabe ressaltar que a questão racial não era o foco desses estudos e que trabalhos sobre o tema ainda são escassos na literatura educacional brasileira (Soares, Gonzaga-Alves, 2003; Bonamino, Franco, Alves, 2005).

A necessidade que muitos alunos, principalmente da $8^{\mathrm{a}}$ série do ensino fundamental, possuem de conciliar os estudos com o trabalho é um dos fatores relacionados com a repetência escolar. A análise da tabela 3 revela que 63\% dos alunos que trabalham possuem experiência prévia de repetência. A iniciativa e programas de complementação de renda familiar podem atenuar o problema. Este é o caso da Bolsa-Escola, criado em 200 I, com a proposta de conceder benefício monetário mensal a milhares de famílias brasileiras em troca da manutenção de suas crianças nas escolas.

Nas seções anteriores, mostramos que os diferentes tipos de capital (econômico, cultural e social) estão relacionados com o desempenho escolar. Vimos que uma das principais fontes de mobilização do capital social situa-se nas relações internas da família. $O$ conceito de capital social é usualmente operacionalizado com medidas de qualidade e de quantidade de tempo que os pais gastam com os filhos. Nesse caso, fatores como tamanho das famílias e estrutura familiar ganham destaque. Muitos autores argumentam que quanto mais filhos (crianças), menos tempo os pais têm para se dedicar a cada um deles. Portanto, o número de filhos é um indicador de capital social familiar, não obstante um indicador negativo. Essas investigações indicam que o capital social pode ser maior nas famílias nas quais os pais vivem juntos e têm poucos filhos, uma vez que o somatório dessas condições promove maior atenção dos pais e mais horas dedicadas aos filhos. 
Como medida de capital social, utilizamos as respostas dos alunos da $8^{a}$ série à seguinte pergunta do questionário contextual do Saeb 200 I: "Quantas pessoas moram com você?" As categorias de respostas foram recodificadas de forma a assumir o valor I se, na residência do aluno, morarem quatro ou mais pessoas. Os resultados mostrados na tabela 3 sobre esse tema mostram que a porcentagem de repetentes é maior entre os alunos em cuja residência moram quatro ou mais pessoas (50\%) em comparação com alunos que em suas residências moram até três pessoas (43\%).

Um indicador de recursos educacionais familiar (Mollenar, 1997) foi construído com base nas respostas aos questionários sobre a existência dos seguintes itens na casa dos alunos: um jornal diário, revistas de informação geral, uma enciclopédia, um atlas, um dicionário e uma calculadora. A seguir somaram-se os valores em cada variável, particionados posteriormente em dois percentis, que assumem valor I para os alunos que possuem médio ou alto acesso aos recursos educacionais. A existência desses recursos na residência dos alunos sinaliza um grau de mobilização da rede de apoio familiar, principalmente, entre aquelas famílias que possuem tais itens, a despeito de ter condição econômica para tal, indicando uma valorização familiar das formas escolares de aprendizagem.

Com base na tabela 3 observa-se que o percentual de repetência entre os estudantes cujas famílias possuem recursos educacionais acima da média é de $43 \%$. Já entre os estudantes cujas famílias possuem baixos níveis de recursos educacionais a percentagem sobe para $55 \%$.

No que diz respeito aos inúmeros estudos quantitativos que têm investigado aspectos dos diferentes tipos de capital, a instrução familiar é um dos mais recorrentes. Com freqüência a instrução familiar apresenta um forte impacto nas questões relacionadas à vida escolar como, por exemplo, resultados escolares e continuidade dos estudos. Neste estudo, o indicador de escolaridade familiar é o número mais alto entre os anos de estudos do pai e da mãe do aluno. As variáveis "escolaridade do pai" e "escolaridade da mãe" foram recodificadas da seguinte forma: I - não estudou; 2 - estudou até a $4^{\text {a }}$ série; 3 - estudou até a $8^{\text {a }}$ série; 4 - completou o ensino médio e 5 - possui ensino superior.

Sobre este aspecto a tabela 3 mostra que o percentual de repetentes entre alunos cuja família tem ensino superior é de $35 \%$. Já entre alunos cujos pais não possuem instrução a porcentagem sobe para $60 \%$. 
Um indicador de posse de bens econômicos foi construído a partir das respostas aos questionários sobre a existência e/ou disponibilidade dos seguintes itens na casa dos alunos: número de aparelhos de televisão em cores; número de aparelhos de videocassete; número de geladeiras; número de freezer; número de máquinas de lavar roupas; número de computadores; número de automóveis. A seguir somaram-se os valores em cada variável, particionados posteriormente em dois percentis, que assumem valor I para aqueles alunos que possuem médio ou alto acesso a recursos econômicos.

Os resultados sobre posse de bens econômicos mostram que os alunos que se situam abaixo da média quanto à posse de bens econômicos apresentam um percentual de repetência maior (52\%) em comparação com os alunos que possuem posse de bens econômicos acima da média, cujo percentual é de $42 \%$.

O percentual de repetência é menor entre os alunos que afirmam gostar de Matemática em comparação àqueles que afirmam não gostar de dessa disciplina (44\% e 54\%, respectivamente).

Os resultados descritivos apresentados indicam tendências e sugerem variáveis relevantes para a análise de risco. No entanto, não se pode pressupor que os resultados descritivos devam se impor na análise multivariada. tema deve ser aprofundado por meio da estimação de modelos de risco para repetência. É o que mostraremos a seguir.

\section{Modelo de risco para repetência}

Nesta seção apresentaremos os resultados da estimação do modelo de risco de repetência para os alunos da $8^{a}$ série do ensino fundamental das escolas públicas das capitais brasileiras. $\bigcirc$ quadro I apresenta as razões de chance - OR - estimadas para as variáveis incluídas nos dois modelos estimados. Para facilitar a leitura, destacamos em negrito as categorias de referência.

Inicialmente, discutimos o resultado do modelo I. As variáveis "menino" e "trabalha" apresentam-se como fatores de risco para a repetência dos alunos da $8^{\text {a }}$ série do ensino fundamental de escolas públicas das capitais brasileiras. Alunos do sexo masculino apresentam maior chance de repetência do que as meninas $(O R=1,49)$. Da mesma forma, os alunos inseridos no mercado de trabalho apresentam maior chance de repetência em relação àqueles que 


\section{QUADRO I \\ MODELO DE RISCO DE REPETÊNCIA PARA ALUNOS DA \& S SÉRIE DAS ESCOLAS PÚBLICAS DAS CAPITAIS BRASILEIRAS}

\begin{tabular}{|c|c|c|}
\hline \multirow[t]{2}{*}{ Variáveis } & Modelo I & Modelo 2 \\
\hline & \multicolumn{2}{|c|}{ Razão de chance (OR) } \\
\hline Posse de bens abaixo da média & - & - \\
\hline Posse de bens acima da média & $0,82 * * * *$ & 0,74 ***** \\
\hline Branco & - & - \\
\hline Pardo & $1,2 \mid$ 米米 & $1,18 * * *$ \\
\hline Preto & $1,85^{*} * *$ & I,38***⿻丷木 \\
\hline Menina & - & - \\
\hline Menino & 1,49**** & I,, $49 * * * *$ \\
\hline Não Trabalha & - & - \\
\hline Trabalha & $2,00 * * *$ & $2,01 * * * *$ \\
\hline Mora com menos de 4 pessoas & - & - \\
\hline Mora com mais de 4 pessoas & I,3|米米 & $|, 3|$ **⿻丷木大 \\
\hline Está abaixo da média em comparação aos colegas & - & - \\
\hline Está na média ou acima da média em comparação aos colegas & $0,66^{* * * *}$ & $0,74^{* * * *}$ \\
\hline Não gosta de estudar matemática & - & - \\
\hline Gosta de estudar matemática & $0,70 * * * *$ & 0,72 ***** \\
\hline Tem recursos educacionais abaixo da média & - & - \\
\hline Tem recursos educacionais acima da média & 0,70 ***** & 0,70 ***** \\
\hline Instrução familiar até $8^{\mathrm{a}}$ série & - & - \\
\hline Família sem instrução ou com instrução até $4^{a}$ série & $1,22 * * * *$ & 1,22 ***** \\
\hline Instrução familiar até I I a série & $0,78^{*} * * *$ & $0,78^{* * * *}$ \\
\hline Instrução familiar ensino superior & $0,74 * * * *$ & $0,76 *$ **** \\
\hline \multicolumn{3}{|l|}{ Termo de interação } \\
\hline Posse de bens acima da média $\times$ preto & & $2,03 * * * *$ \\
\hline Posse de de bens acima da média $\times$ pardo & & n.s. \\
\hline constante & 1,08 & 1,07 \\
\hline Deviance & 12,649 & $12,605 \#$ \\
\hline
\end{tabular}

**** p-valor <0,0 I; n.s. estatisticamente indistinto de I a 95\%.

\# Redução da deviance do modelo I para o modelo 2 é estatisticamente significativa a 99\%.

Fonte: Microdados do Saeb 200 I, elaboração dos autores. 
não estão trabalhando $(O R=2,0)$. A chance de repetência de um aluno da $8^{a}$ série em escolas públicas das capitais brasileiras que se autodeclara preto é maior do que a dos alunos que se consideram brancos. $\bigcirc$ mesmo acontece para os alunos que se autodeclaram pardos, ainda que o risco para estes últimos seja menor ( $O R=1,85$ e I,2 I, respectivamente).

Já as variáveis relacionadas com à motivação e autopercepção do aluno (gosta de estudar Matemática e está acima da média em comparação aos seus colegas) apresentam-se como fatores de proteção da repetência. Os alunos que afirmam gostar de estudar matemática apresentam chances de repetência menores do que seus colegas que dizem não gostar da disciplina.

Com relação ao efeito do capital cultural sobre o risco de repetência pode-se notar que os alunos cujos pais não têm instrução ou cursaram até a $4^{\mathrm{a}}$ série do ensino fundamental apresentam maior chance de repetência $(O R=1,22)$ do que os alunos cujas famílias têm instrução até a $8^{a}$ série. Os alunos cujos pais possuem mais de oito anos de instrução apresentam chances menores de repetência, sendo que os alunos que possuem pais com nível superior apresentam chance menor ainda $(O R=0,78$ e $O R=0,74$, respectivamente). Como vimos anteriormente, a instrução dos pais é um dos fatores que mais se relaciona com o desempenho escolar dos estudantes e, no caso da repetência, quanto maior a instrução, menor é o risco de ocorrência desse fenômeno.

A presença de capital econômico no meio familiar também é um fator de proteção da repetência $(O R=0,8 \mid 7)$, ou seja, os alunos que possuem posse de bens econômicos acima da média apresentam menor chance de repetência em comparação àqueles estudantes que não possuem capital econômico elevado.

Com relação aos efeitos do capital social sobre o risco de repetência observa-se que a variável "mora com mais de quatro pessoas" é um fator de risco $(O R=|, 3|)$, em conformidade com estudos que argumentam que uma quantidade grande de moradores por domicílio pode prejudicar a dedicação que os pais têm à vida escolar dos filhos.

A variável "recursos educacionais familiares" é um fator de proteção $(O R=0,70)$ para repetência. Alunos cuja família disponibiliza recursos educacionais apresentam menor chance de repetência em comparação àqueles que não possuem tais benefícios. 
Esses resultados indicam os efeitos médios das variáveis consideradas. $\mathrm{Na}$ seqüência da análise investigamos o tema da modificação de efeitos. Nosso objetivo é o de responder à seguinte pergunta: o efeito da variável capital econômico é o mesmo para os diferentes grupos raciais? Ou, alternativamente, o capital econômico, construído para este estudo, tem efeito diferenciado para alunos brancos, pardos e pretos? Para responder a essa pergunta foi incluída no modelo de regressão logística uma interação envolvendo as variáveis "alta posse de bens" e "cor declarada". O modelo 2, na tabela 4, apresenta o resultado da razão de chance para as variáveis incluídas no modelo.

Inicialmente, destacamos que o exame do resultado da estimação do modelo 2 indica a estabilidade dos efeitos associados às variáveis não relacionadas com o termo de interação incluído, razão pela qual limitamo-nos a discutir os resultados referentes às variáveis raça e posse de bens. Observe-se que a razão de chance para a variável alta posse de bens passou de 0,82 (modelo I) para 0,74 (modelo 2). É importante notar que no modelo I estimava-se o efeito médio de alta posse de bens para todos os alunos, controlado pelas demais variáveis incluídas nesse modelo. Já no caso do modelo 2 a interpretação é diferenciada, devido à inclusão do termo de interação "posse de bens versus raça". No contexto do modelo 2, o exame direto da razão de chance associada à variável "alta posse de bens", refere-se aos alunos brancos. A apuração da proteção ou risco para os demais grupos envolve a consideração simultânea do efeito principal e do efeito do termo de interação. No caso do grupo de alunos que se autodeclararam pretos temos:

$(\mathrm{OR}$ principal-atta posse de bens $) \times\left(O R_{\text {interação-alta posse de bens } \times \text { pretos }}\right)=0,74 \times 2,03=1,5$

Isso significa que capital econômico é um fator de proteção para alunos brancos, mas não para alunos pretos. Os alunos pretos apresentam maior chance de repetência do que os alunos brancos com o mesmo nível de posse de bens econômicos. No caso dos alunos pardos estimou-se para o termo de interação valor igual à unidade, o que indica que o efeito da variável posse de bens para esses alunos não é distinto do efeito da posse de bens para alunos brancos. 


\section{CONCLUSÕES}

Este estudo teve por finalidade estudar os efeitos dos diferentes tipos de capital no risco de repetência escolar. No fundamental, os resultados reproduzem os achados usuais da literatura, que já sinalizava que diversas variáveis sociodemográficas aumentam o risco de reprovação (trabalho, ser do sexo masculino e ser preto). Por sua vez, o maior capital econômico é fator de proteção para reprovação. Neste trabalho mostramos que capital econômico não protege a todos igualmente. Em especial, alto capital econômico aumenta o risco de reprovação de alunos que se autodeclaram pretos. Este resultado precisa ser compreendido no contexto da dinâmica das políticas de reprovação e de alocação de alunos em escolas. No Brasil, aprovação e reprovação são, tipicamente, políticas de unidades escolares, decididas de modo relativamente autônomo pelas escolas. Já a alocação dos alunos em escolas é fortemente influenciada pela situação econômica dos alunos, especialmente pela via da relação entre situação econômica das famílias e local de residência. Famílias negras que possuem melhor situação econômica tendem a ter melhores opções de moradia, o que pode abrir-lhes o acesso a escolas com melhores condições de ensino. No entanto, isto pode colocar seus filhos no grupo de maior risco de reprovação nessas escolas. Os achados desta pesquisa são compatíveis com essa dinâmica, sinalizando que o tema da desigualdade racial no Brasil não se reduz a um acontecimento estritamente econômico.

\section{REFERÊN CIAS BIBLIO GRÁFICAS}

ALBERNAZ, A.; FERREIRA, F. H.; FRANCO, C. A Escola importa? Determinantes da eficiência e eqüidade no ensino fundamental brasileiro. Pesquisa e Planejamento Econômico, Rio de Janeiro, v.23, n.3, p.453-476, 2002.

BARBOSA, M. E. et al. Modelagem multinível dos dados do Saeb 1999: relatório técnico. Rio de Janeiro: Ence; IBGE, $200 \mathrm{I}$.

BARROS, R.; HENRIQUES, R.; MENDONÇA, R. Education and equitable economic development. Economia, v. I, n. I, p. I I I-I44, 2000.

BONAMINO, A.; FRANCO, C.; ALVES, F. The Color of educational inequalities. Brazil. 
In: GLOBAL CONFERENCE ON EDUCATION RESEARCH IN DEVELOPING COUNTRIES. Praga, 31 mar./ 2 abr.2005. [Trabalho apresentado]

BONAMINO, A.; FRANCO, C.; FERNANDES, C. Repetência escolar e apoio social familiar. um estudo a partir dos dados do Saeb 200 I. (Relatório técnico: estudo PUC-Rio, 2.) Disponível em: http://www.inep.gov.br/basica/saeb/publicacoes.htm. Acesso em: abr.2005. BRANDAO, Z.; BAETA, A. M.; ROCHA, A. D. Evasão e repetência no Brasil: a escola em questão. Rio de Janeiro: Achiamé, 1983.

COLEMAN, J. S. Social capital in the creation of human capital. American fournal of Sociology, v.94, p.S95-S120, 1988.

BRASIL. Ministério da Educação. Microdados do Saeb 200/. Brasília, 2001 .

COSTA-RIBEIRO, S. A Pedagogia da repetência. Estudos Avançados, v.5, n. 12, p.7-21, maio/ ago. 1991 .

FORQUIN, J-C. Evoluções recentes do debate sobre a escola, a cultura e as desigualdades na França. In: FRANCO, C. (org.) Avaliação, ciclos e promoção na educação. Porto Alegre: Artmed, 200I. p. 101 - 120.

FRANCO, C.; MANDARINO, M.; ORTIGÃO, M. I. R. O Impacto do projeto pedagógico de escola nos resultados escolares. Pesquisa e Planejamento Econômico, Rio de Janeiro, v.23, n.3, p.477-497, 2002.

FREITAS, M. A. T. A Escolaridade média no ensino primário brasileiro. Revista Brasileira de Estatística, v.8, n.30/3 I, p. 295-474, 1947.

GOMES-NETO, J. B.; HANUSHEK, E. A. Causes and consequences of grade repetition: evidence from Brazil. Economic Development and Cultural Change, v.43, n. I, p. I 17-49, 1994.

INSTITUTO NACIONAL DE ESTUDOS E PESQUISAS EDUCACIONAIS - INEP. Saeb 200/: novas perspectivas. Brasília, 2002.

LAHIRE, B. Sucesso escolar nos meios populares: as razões do improvável. São Paulo: Ática, 1997.

LEON, F. L. L.; MENEZES-FILHO, N. Reprovação, avanço e evasão escolar no Brasil. Pesquisa e Planejamento Econômico, Rio de Janeiro, v.32, n.3, p.4I7-45I , 2002.

MADEIRA, F. R.; RODRIGUES, E. M. Recado dos jovens: mais qualificação. In: BERQUÓ, E. (org.) Jovens acontecendo na trilha das politicas públicas, 2. Brasilia: CPND, 1998. p.427498. 
MOLENAAR, I. W. Nonparametric models for polytomous responses. In: VAN DER LINDEN, W. J.; HAMBLETON, R. K. (eds.) Handbook of modern item response theory. New York: Springer, 1997. p.369-380.

NOGUEIRA, M. A. Trajetórias escolares, estratégias culturais e classes sociais: notas em vista da construção de um objeto de pesquisa. Teoria \& Educação, Porto Alegre, n.3, p.89-1 19 , 1991.

PATTO, M. H. A Produção do fracasso escolar. histórias de submissão e rebeldia. 2.ed. São Paulo: Casa do Psicólogo, 1996.

ROMANELLI, G. O Significado da escolarização superior para duas gerações de famílias de camadas médias. In: VEIGA-NETO, A. J. (org.) Sociologia da educação. Porto Alegre: Anped, 1994. p.43-64.

SOARES, J. F; GONZAGA-ALVES, M. T. Desigualdades raciais no sistema brasileiro de educação básica. Educação e Pesquisa, v.29, n. I, p. 147-165, 2003.

SOUZA, A. M.; SILVA, N. V. Origem familiar, qualidade da educação e escolas públicas em São Paulo: relações e efeitos nas transições escolares. Pesquisa e Planejamento Econômico, v.24, n. I, p.97-1 | 4, 1994.

WILLMS, D. J. Proposal for the measurement of socio-economic status for the focused component of the student questionnaire for the OECD programme for international student assessment. OECD-PISA, 1998. mimeo.

Recebido em: maio 2006

Aprovado para publicação em: junho 2006 